\title{
Health in a cold climate
}

The British economy is edging out of a severe economic recession, during which the future of international financial systems seemed in doubt. The scale of debt is comparable to that following the Second World War, and national borrowing is predicted to reach $80 \%$ of gross domestic product by 2013. We have suffered a permanent loss in national output of $6-7 \%$. The inevitable reduction in funding for public services is already being discussed widely by the political parties. It is timely to consider the possible impacts on the NHS, which has enjoyed real increases in funding of almost $7 \%$ per year in England up to $2010 / 11$, overall and on general practice.

These challenges have been addressed in an analysis undertaken by the King's Fund and the Institute for Fiscal Studies. How cold will it be ? $^{1}$ analyses the funding consequences for the NHS over the next 6 years. Three possible funding scenarios are described: 'tepid', with annual real increases of 2-3\% over the next 6 years; 'cold', with no change in NHS funding; and 'arctic', with annual reductions of $1-2 \%$ in funding up to $2016 / 17$. All three scenarios would lead to significant reductions in funding across non-NHS government spending departments, particularly if NHS funding is protected. The magnitude of the funding gaps is such that if the NHS were to receive even a modest increase in real spending, a permanent increase in tax of over $£ 17$ billion would be required by 2016 , equivalent to $£ 540$ per family and to an increase in value-added tax (VAT) of $4.5 \%$. If NHS funding were frozen, these figures would equate to $£ 6.9$ billion, £220 per family, and an increase in VAT of $1.6 \%$ respectively.

Not only are increased NHS costs related to changing population demography already predicted to be around £1.1-1.4 billion per annum, but also all three of the scenarios fall well short of the recommendations for NHS funding described in the Wanless report. ${ }^{2}$ For example, the most optimistic (tepid) scenario combined with Wanless' most optimistic (fully engaged) scenario, would lead to a funding shortfall of £4 billion; but the two less optimistic, and probably more realistic, cold and arctic scenarios, combined with the worst-case scenarios envisaged by Wanless, could lead to funding gaps of between £21-40 billion at today's prices. This represents almost $30 \%$ of the current NHS spend in England. It is extremely unlikely that increasing NHS 'productivity' is capable of filling this gap, so that a decrease in NHS funding in England over the next 6 years of $£ 20$ billion is a real possibility.

Unsurprisingly, strategic health authorities and primary care trusts have begun to consider how to cope with these financial constraints. A recent report published by the British Medical Association $^{3}$ in response to plans published by NHS London, ${ }^{4}$ describes a number of strategies which will have major implications for general practice and primary care. As well as proposed reductions in a range of hospital activities, including elective procedures, outpatient appointments, and investigations, London's NHS On the Brink $^{3}$ reports plans to shift $55 \%$ of outpatient services and $60 \%$ of accident and emergency activity to 'polysystems', to pay GPs on a fee-for-service basis for extended hours and out-of-hours cover, and to reduce GP consultation times by $33 \%$ and prescribing costs by $10-15 \%$.

For this issue of the BJGP we asked a range of commentators how they would approach the current funding crisis. If cuts must happen, what to cut?

A general theme, unsurprisingly, is that frontline clinical services should be preserved. There is demand that expenditure on managers and administration must fall. Centralised and expensive IT projects may no longer be affordable, even when they work. Expenditure on assessment and measurement activity should be reduced or, at the very least, proceed only after proven efficacy and cost-effectiveness.

In previous cycles of expansion followed by retrenchment in healthcare funding the historical precedent is not encouraging. When spending on health care increases much of the investment goes into expanding management first and clinical capacity second. However when spending is constrained clinical capacity is the first to shrink. ${ }^{5} \mathrm{~A}$ crucial priority this time around is that this precedent is not followed.

We believe that spending decisions should hinge on three important principles. First, strong primary care is the foundation of a successful equitable healthcare system that delivers good outcomes. It is not special pleading that allows us to assert that primary care must be the last part of a healthcare system to be cut - there is hard evidence that strong primary care can salvage our healthcare system. Barbara Starfield's work needs no further introduction, ${ }^{6}$ and the health secretary in England recently celebrated the publication of the Commonwealth Fund report. ${ }^{7}$

Second, remember what is at the heart of what we do in general practice, where over $80 \%$ of patient-doctor contact in the NHS occurs. The consultation is the most crucial, constructive, and potentially productive exchange within our healthcare system (think of prescribing decisions, think of gatekeeping). We should use it as the starting point in making difficult spending (and cutting) decisions. Fund the health service at that central core - the further away from the core, the more challenging it is likely to become to justify protecting current expenditure.

Finally, decision making about spending and cutting must be informed by clinicians and their patients, particularly in primary care. Our contributors brim with enthusiasm, commitment, pragmatism, and wisdom. Clinicians need to stand up and be counted.

\section{Roger Jones and Alec Logan}

Editor and Deputy Editor, BJGP.

\section{Provenance}

Freely submitted; peer reviewed. 


\section{REFERENCES}

1. Appleby J, Crawford R, Emmerson C. How cold will it be? Prospects for NHS funding: 2011-17. London: The King's Fund, 2009.

2. Wanless D. Securing good health for the whole population: Final report - February 2004. London: The Stationery Office, 2004

3. Lister J. London's NHS On the Brink. London: BMA London Region, 2009.

4. NHS London. Delivering healthcare for London: An integrated strategic plan 2010-15. First Stage Report. http://www.london.nhs.uk/webfiles/Corporate/HFL\%2 0-\%20First\%20Stage\%20Report\%20-\%20v2.pdf (accessed 16 Feb 2010).

5 Clark T. UK public spending by government department. Guardian 2009; 30 Sep:

http://www.guardian.co.uk/news/datablog/2009/sep/16/ public-spending-departments-money-cuts (accessed 15 Feb 2010)

6 Barbara Starfield

http://faculty.jhsph.edu/default.cfm?F=Barbara\&L=Star field (accessed 15 Feb 2010)

7 Schoen C, Osborn R, Doty MM, et al. A survey of primary care physicians in 11 countries, 2009: perspectives on care, costs, and experiences. http://www.commonwealthfund.org/Content/Publicati ons/In-the-Literature/2009/Nov/A-Survey-of-PrimaryCare-Physicians.aspx (accessed 15 Feb 2010).

DOI: 10.3399/bjgp10X483481

\section{ADDRESS FOR CORRESPONDENCE}

Roger Jones and Alec Logan

BJGP Office, Royal College of General

Practitioners, 14 Princes Gate, Hyde Park,

London SW7 1PU.

E-mail: journal@rcgp.org.uk 